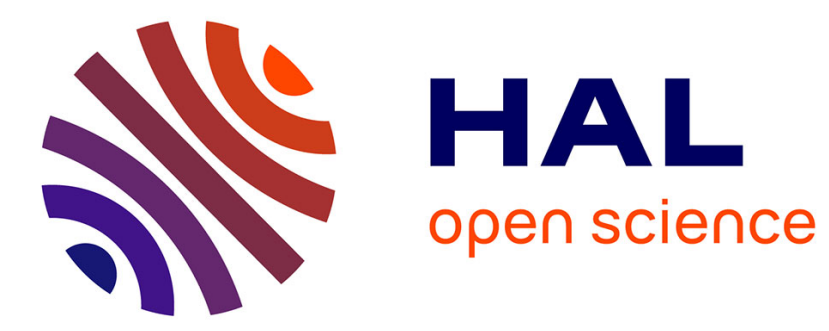

\title{
Self-reported competence of Estonian community pharmacists in relation to herbal products: findings from a health-system in transition
}

Daisy Volmer, John Lilja, David D Hamilton, J Simon Bell, Peep Veski

\section{- To cite this version:}

Daisy Volmer, John Lilja, David D Hamilton, J Simon Bell, Peep Veski. Self-reported competence of Estonian community pharmacists in relation to herbal products: findings from a health-system in transition. Phytotherapy Research, 2010, 10.1002/ptr.3266 . hal-00599837

\section{HAL Id: hal-00599837 https://hal.science/hal-00599837}

Submitted on 11 Jun 2011

HAL is a multi-disciplinary open access archive for the deposit and dissemination of scientific research documents, whether they are published or not. The documents may come from teaching and research institutions in France or abroad, or from public or private research centers.
L'archive ouverte pluridisciplinaire HAL, est destinée au dépôt et à la diffusion de documents scientifiques de niveau recherche, publiés ou non, émanant des établissements d'enseignement et de recherche français ou étrangers, des laboratoires publics ou privés. 


\section{Self-reported competence of Estonian community pharmacists in relation to herbal products: findings from a health-system in transition}

\begin{tabular}{|c|c|}
\hline Journal: & Phytotherapy Research \\
\hline Manuscript ID: & PTR-10-0153.R1 \\
\hline Wiley - Manuscript type: & Full Paper \\
\hline $\begin{array}{r}\text { Date Submitted by the } \\
\text { Author: }\end{array}$ & 14-Jun-2010 \\
\hline Complete List of Authors: & $\begin{array}{l}\text { Volmer, Daisy; University of Tartu, Department of Pharmacy } \\
\text { Lilja, John; Abo Akademi University, Department of Pharmacy } \\
\text { Hamilton, David; University of Glasgow, Recruitment, Admissions } \\
\text { and Participation Service } \\
\text { Bell, J Simon; University of Eastern Finland, 5Clinical Pharmacology } \\
\text { and Geriatric Pharmacotherapy Unit, School of Pharmacy, Faculty of } \\
\text { Health Sciences } \\
\text { Veski, Peep; University of Tartu, Department of Pharmacy }\end{array}$ \\
\hline Keyword: & herbal products, extended community pharmacy services, Estonia \\
\hline
\end{tabular}

\section{S) ScholaroNE \\ Manuscript Central}




\section{INTRODUCTION}

Complementary and alternative medicine (CAM) has been defined as a group of diverse medical and health care systems, practices, and products that are not generally considered part of conventional medicine (Barnes, 2003). Herbal products are one component of CAM, and include both herbal supplements and herbal medications. Herbal supplements, used by some individuals to supplement traditional medical therapies, are not considered as medications and in general are not regulated by drug agencies (Definition of herbal supplement, 2009). Herbal medications have active constituents with known pharmacological effects and they are able to cause side effects and interactions. Herbal medications are usually dispensed by retail pharmacies without prescription and are often regulated as medicinal products (Holst et al., 2009).

The 2007 National Health Interview survey conducted in the US revealed that $74 \%$ of adults and $53 \%$ of children had used herbal supplements in the past 30 days (National Health Interview Survey, 2007). A similar increase in the use of CAM has been reported in European countries (Thomas et al., 2001).

In Europe legislation concerning herbal medications was not harmonized until 2001. Prior to European harmonization each country was responsible for its own regulations concerning herbal medicines. In Germany, the therapeutic guide to herbal medicine issued in 1998 contained descriptions of 380 medicinal plants (The Complete German Commission E Monographs, 1999). Requirements for obtaining a marketing authorisation for traditional herbal medicinal products were first presented in the EU 
Directive 2001/83/EC. This directive was later replaced with Directive 2003/63/EC

(Commission Directive 2003/63/EC amending Directive 2001/83/EC, 2003).

\section{Healthcare reforms in Estonia}

Estonia is a small northern European country (population 1.3 million) located to the south of Finland. Unlike in many European and North American countries there is a long tradition of herbal product use in Estonia. However, the traditions associated with herbal product use are evolving in line with the recent healthcare reforms. Since independence from Soviet Union was restored in 1991 the Estonian health care system has undergone a process of rapid transition. This transition has involved the shift from a centralized, specialist-orientated system to a system based on primary health care and evidence-based medicine (Põlluste et al., 2005). Under these changes the operation of community pharmacies was transferred from the State to private ownership (Volmer et al., 2008).

Estonia joined the European Union (EU) in 2004. Pharmacies in Estonia continue to have a monopoly on the sale of prescription and non-prescription medications, including herbal products. Consumers perceive pharmacists as trustworthy sources of information about prescription and non-prescription drugs (Volmer et al., 2009). However, pharmacy practice and policy in Estonia is increasing shaped by reforms at the European level.

The healthcare reforms described above have created two approaches to the use of herbal products in Estonia. The first approach is based on traditions and practice experience. The second approach is based on evidence-based medicine and scientific research. These approaches are not necessarily mutually exclusive. Estonian pharmacists are increasingly 
required to marry these approaches to meet the healthcare needs and expectations of their customers.

\section{Regulation and use of herbal medications and herbal supplements in Estonia}

Legislation related to herbal medicinal products in Estonia follows EU directives. The State Agency of Medicines (SAM) is the institution responsible for categorization of herbal products as medicines or supplements and for licensing of herbal medicinal products. The categorization is made on the basis of the safety of the active components (Medicinal Products Act, 2005). The Estonian Health Care Board is responsible for registration of herbal supplements. However, detailed requirements for the quality, efficacy and safety of herbal supplements have not been developed in Estonia. Currently, the importer of herbal supplements must obtain a quality certificate for each herbal product. Although both herbal medicinal products and supplements are sold in community pharmacies, it is often challenging for pharmacists to access and provide evidence-based information in relation to the quality, efficacy and safety of the herbal supplements.

The use of herbal products has been traditional and popular in Estonia. In 2002 the most popular herbal products were teas for the treatment of minor urinary and upper respiratory tract complaints, followed by stress-relieving remedies and teas to provide a “good night's sleep” (Püüa, 2004). Estonians often use herbal products as the first remedy to treat minor illnesses. Information concerning the mode of action and indication 
is typically obtained from previous experience or provided by a health care professional, usually a pharmacist (Volmer et al., 2007).

The only formal education about medicinal plants and herbal products provided to pharmacists in Estonia is during the five-year Master of Pharmacy degree program at the University of Tartu (Evaluation of pharmacy training, 2001). Unlike in many other European countries there are no herbalists in Estonia. In addition, there are very few "health shops" in Estonia from where it is possible to purchase herbal supplements, natural and wellness products, cosmetics and other products.

\section{Attitudes of pharmacists towards herbal products}

A systematic review of 19 studies of US and Canadian pharmacists reported both positive and negative attitudes toward the safety and efficacy of dietary supplements (Kwan, et al., 2006). Despite the fact a large proportion of pharmacists received questions about dietary supplements from patients and other health professionals, pharmacists perceived their knowledge was inadequate and recognized the need for additional training. The need for more training in relation to CAM has also been reported among Australian pharmacy students (Tiralongo, et al., 2008). This need may be reinforced by the expectations of patients who consider pharmacists to be knowledgeable about natural health products (Kwan, et al., 2008). Most published studies investigating the attitudes of pharmacists and pharmacy students toward CAM have been conducted in North America, Asia, Australia and England (Barnes, et al., 2007; Olatunde, et al., in press). No previous 
studies have investigated the attitudes of pharmacists toward use of herbal medications and herbal supplements in this health system in transition.

\begin{abstract}
The objectives of the study were to (1) explore the self-reported competency of pharmacists in relation to herbal medicines and herbal supplements, and (2) investigate the self-reported provision of community pharmacy services in relation to herbal medicines and herbal supplements. In the context of the current article the herbal medicines and herbal supplements are referred to together as herbal products.
\end{abstract}

\title{
METHODS
}

\section{Sample and data collection}

A random sample of $50 \%(n=154)$ of community pharmacies in Estonia was extracted from the Register of pharmacies maintained by the Estonian State Agency of Medicines in February 2005. Each pharmacy in the sample was mailed one copy of the survey instrument and a cover letter. The cover letter requested that the survey instrument should be completed by the pharmacist or assistant pharmacist responsible for managing the sale of non-prescription medications. All pharmacies were provided with a pre-paid addressed envelope to return the survey instrument. A reminder was sent by e-mail to all pharmacies after 2 weeks. All survey instruments were completed anonymously.

\section{Survey instrument}

The survey instrument used in the study was adapted from an instrument previously used to survey a stratified random sample of community pharmacists in the US (Bouldin, et 
al., 1999). The survey instrument included items related to (1) the respondent's demographic characteristics, (2) the frequency of consumer requests for information about herbal products, (3) the perceived importance of different determinants of herbal product use, (4) the perceived importance of different aspects of herbal product information, (5) the respondent's self-reported competency in relation to herbal products, and (6) problems encountered by the respondents in relation to proving advice about herbal products. The content validity of the survey instrument was assessed by a panel of 8 researchers and practitioners with an interest in CAM. The survey instrument was pilot tested for face validity among a convenience sample of five pharmacists. Minor changes to the wording of the items were made based on the feedback received. A copy of the survey instrument can be obtained by contacting the corresponding author.

\section{Statistical analyses}

All data analyses were performed using the Statistical Package for the Social Sciences (SPSS, Version 11.0, Chicago, IL). Differences between groups of pharmacists were compared using chi square tests for categorical variables and independent samples t-tests for continuous variables. Younger pharmacists were defined as the respondents aged 2545 years, whereas older pharmacists were those aged 46-65 years. Urban pharmacies were defined as pharmacies located in the official cities, whereas rural pharmacies were defined as pharmacies located in the villages. Differences in pharmacists' attitudes were examined according to age and location of the pharmacy. The level of statistical significance was set at $\mathrm{p} \leq 0.05$. 


\section{RESULTS}

\section{Demographic characteristics of the respondents}

Of the 154 questionnaires distributed $120(77.9 \%)$ were returned, $89(74.1 \%)$ from city pharmacies and $31(25.9 \%)$ from rural pharmacies. Of the respondents, $114(95.0 \%)$ were pharmacists and $6(5.0 \%)$ were assistant pharmacists. All of the respondents were women. The mean age \pm SD of the pharmacists was $42.5 \pm 17.8$ years, and the mean age of the assistant pharmacists was $39.1 \pm 15.4$ years. The pharmacists had a mean of $17.5 \pm$ 14.6 years working experience while the assistant pharmacists had a mean of $14.5 \pm 13.8$ years working experience.

\section{Professional competency of pharmacists}

Seventy-seven $(64.1 \%)$ respondents self-reported their professional knowledge regarding herbal products as good or excellent. Continuing education regarding herbal products was rated as important by $35.8 \%$ of the pharmacists $(n=43)$. Pharmacists stated that the best ways of obtaining professional knowledge were written information $(n=75) 62.5 \%$ and lectures and seminars $(n=75) 62.5 \%$. Pharmacists were less likely to view visits from drug representatives $(n=47) 39.1 \%$ and electronic databases $(n=43) 35.8 \%$ as important sources of professional knowledge. Pharmacists would like to receive more information about unknown medicinal plants $(n=83) 69.1 \%$, safety $(n=69) 57.5 \%$ and the mode of action $(n=65) 54.2 \%$ of herbal products. 
Self-reported professional knowledge was higher among older rather than younger pharmacists $(\mathrm{p}=0.043)$. Younger pharmacists were more likely to prefer electronic databases $(p=0.027)$ and visits from drug representatives $(p=0.032)$ as sources of information about herbal products. Among the respondents, $15.8 \%(n=19)$ had experienced problems counselling about herbal products, $35.0 \%(n=42)$ reported no problems counselling about herbal products and $49.2 \%(n=59)$ reported they occasionally encountered problems counselling about herbal products. Of the $65.0 \%(n=78)$ of pharmacists who indicated they encountered or occasionally encountered problems, $29.5 \%(n=23)$ said this was due to a lack of professional knowledge, $28.2 \%(n=22)$ commented on the need for more detailed patient information leaflets and $25.6 \%(\mathrm{n}=20)$ said they encountered problems because the public misunderstood herbal products. Urban pharmacists were more critical towards the quality of patient information leaflets $(\mathrm{p}=0.027)$, and the difficulty encountered when pharmacy customers lacked knowledge of herbal products $(\mathrm{p}=0.035)$, than were rural pharmacists.

\section{Customer of herbal products}

According to pharmacists, customers routinely came to the pharmacy for information only $45.8 \%(n=55)$ or to ask for information and purchase herbal products $60.8 \%(n=73)$. According to the pharmacists, the typical customers were a 41-60 year old woman and a 61 years or older man, both from the city. Respondents from urban pharmacies perceived a higher customer interest in herbal products than respondents from rural pharmacies $(\mathrm{p}=0.032)$. More than half of the pharmacists surveyed considered that herbal product 
advertisements in the mass media was the most common sources of information about herbal products used by pharmacy customers (Figure 1).

Insert Figure 1 here.

Information about herbal products mode of action, administration, side effects and interactions were considered most important by the survey respondents (Figure 2). Younger pharmacists were more likely than older pharmacists to consider information about safety as important $(\mathrm{p}=0.039)$.

Insert Figure 2 here.

\section{DISCUSSION}

This was the first study in Estonia to investigate the attitudes and knowledge of the pharmacists towards herbal products and their consumption. The results of the study provide an insight into the role of pharmacists in relation to the use of herbal products in this health-system in transition.

Sixty four percent of the respondents self-reported that they possessed good knowledge in relation to herbal products. This self-reported level of knowledge was higher than in surveys of pharmacists conducted in other countries. A Finnish study reported that $38 \%$ 
and $17 \%$ of pharmacy owners believed they knew sufficient information about herbal medicines and herbal supplements respectively (Fock, et al., 2004). A survey of pharmacists and attendees at series of international conferences conducted in Singapore reported that $81 \%$ pharmacists felt they had inadequate skills and knowledge to counsel patients on herbal medications (Koh, et al., 2003). A survey of Australian pharmacists reported that just $15 \%$ reporting they were "very confident" in answering queries about safety, interactions or benefits of CAMs (Semple, et al., 2006). This was despite an earlier study finding that $91 \%$ of Australian pharmacists believe it is important to have knowledge of both CAM and conventional medicine to be able to inform patients about their treatment options (Naidu, et al., 2005).

Despite high number of pharmacists self-reporting good knowledge, only $35 \%$ of Estonian pharmacists and assistant pharmacists had not experienced any problems in relation to counselling about herbal products. It is likely, therefore, that the problems experienced by the pharmacists did not relate to their perceived lack of knowledge. Estonian pharmacists may have had difficulty accessing evidence-based information about herbal products. Of 200 herbal products available at Estonian pharmacies in 2001, only $50(25 \%)$ had written patient information leaflets (PILs) that contained no errors (Arjakse, 2002). The most common error related to ascribing medical claims to products classified as food supplements. Obtaining evidence-based information about CAMs is also a problem reported internationally. Sources of information about CAMs among pharmacists surveyed in Singapore included books/magazines (64\%), friends/family (35.7\%), and the Internet (31.4\%) (Koh, et al., 2003). The most common sources of 
information among Australian pharmacists were books and journal articles. This led the authors of several studies to conclude that there is a need for greater access to CAM resources and education (Semple, et al., 2006; Olatunde, et al., in press).

It is possible that Estonian pharmacists overestimated their knowledge in relation to CAM and particularly concerning herbal products. While there has been a long tradition of herbal product use in Estonia, recognition of the potential for clinically significant herb-drug interactions is more recent (Volmer, et al., 2006). However, as in previous studies (Cuzzolin, et al., 2009), issues concerning the safety of herbal products were rarely discussed with pharmacy customers (Volmer, et al., 2006). Scientific evidence concerning the safety and efficacy of CAMs is typically derived from only small number of randomized controlled trials (RCTs) (Hu, et al., 2005). Herb-drug interactions may have not been covered in the undergraduate pharmacy curricula when many of the respondents undertook their university-based training. Pharmacy education about herbal products in Estonia is primarily orientated to botany and the chemical constituents of plants rather than the pharmacological activity of the active substances (Evaluation of pharmacy training, 2001). Tools such as the 22-item Consolidated Standards of Reporting Trials checklist may assist pharmacists interpreting the results of RCTs (Gagnier, et al., 2006). However, further research is required to determine how Estonian pharmacists communicate the risks and benefits of CAM and particularly herbal products to Estonian pharmacy customers. 
The majority of Estonian pharmacists self-evaluated their competency in relation to herbal products as good or excellent. However, there was as mismatch between pharmacists' self-evaluated competency and their self-reported provision of advice about herbal products. Health system reforms in Estonia may need to be accompanied by enhanced training for pharmacists to provide advice about the safe and appropriate use of herbal products.

\section{Study strengths and limitations}

An important strength of the study was that the survey instrument was mailed to a random sample of half of all Estonian community pharmacies, and a good response rate was achieved. Estonian community pharmacists and assistant pharmacists are almost exclusively female. However, a limitation of the study was that it did not capture the attitudes of male pharmacists. In addition only 6 assistant pharmacists participated in the survey. Unlike in many other countries in Europe, the number of pharmacists working at community pharmacies is higher than the number of assistant pharmacists. Another reason for the low participation of assistant pharmacists in the survey could be incorrect following of the instructions. The envelop with the survey instrument could be opened and completed by pharmacy manager. As with other attitudinal surveys, it is not clear whether pharmacists' self-reported attitudes correspond with their actual behaviour in the pharmacy workplace. Further research is also needed to determine consumers' attitudes toward pharmacists as providers of information about CAM. 


\title{
REFERENCES
}

2007 National Health Interview Survey.

[http://www.cdc.gov/NCHS/nhis/nhis_2007_data_release.htm] Accessed 08.02.2010.

\begin{abstract}
Arjakse J. Herbal food supplements and natural products in Estonian community pharmacies [in Estonian]. Master's Thesis. University of Tartu, Tartu, Estonia; 2002, 145.
\end{abstract}

Barnes J, Abbot NC. 2007. Professional practice and experiences with complementary medicines: a cross-sectional study involving community pharmacists in England. Int J Pharm Pract 15:167-175.

Barnes J. 2003. Quality, efficacy and safety of complementary medicines: fashions, facts and the future. Part I. Regulation and quality. Br J Clin Pharmacol 55:226-233.
Commission Directive 2003/63/EC amending Directive 2001/83/EC of the European Parliament and of the Council on the Community code relating to medicinal products for human use. [http://www.emea.europa.eu/pdfs/human/pmf/2003-63-EC.pdf] Accessed 08.02.2010.


Bouldin AS, Smith MC, Garner DD, Szeinbach SL, Frate DA, Croom EM.1999.

Pharmacy and herbal medicine in the US. Soc Sci Med 49:279-289.

Cuzzolin L, Benoni G. 2009. Attitudes and Knowledge toward natural Products Safety in the Pharmacy Setting: an Italian Study. Phytother Res 23: 1018-1023.

Evaluation of pharmacy training. Department of Pharmacy, Faculty of Medicine, University of Tartu. Tartu University, Tartu 2001. [http://www.ut.ee/ARFA/report.pdf] Accessed 08.02.2010.

Fock J, Pietilä K. 2004. The knowledge of legislation and information sources on natural health products among pharmacy owners in Finland. Seguim Farmacoter 2:73-85.

Gagnier JJ, Boon H, Rochon P, Moher D, Barnes J, Bombardier C. 2006. Recommendations for reporting randomized controlled trials of herbal interventions: Explanation and elaboration. J Clin Epid 59(11):1134-1139.

Holst L, Wright D, Nordeng H, Haavik S. 2009. Use of herbal preparations during pregnancy: Focus group discussion among expectant mothers attending a hospital antenatal clinic in Norwich, UK. Complement Ther Clin Pract 15:225-229.

Hu Z, Yang X, Ho PC, Chan SY, Heng PW, Chan E, Duan W, Koh HL, Zhou S.2005. Herb-drug interactions: a literature review. Drugs 65:1239-1282. 
Koh H-L, Teo H-H, Ng H-L. 2003. Pharmacists' patterns of use, knowledge, and attitudes toward complementary and alternative medicine. J Altern Complement Med 9(1): 51-63.

\author{
Kwan D, Boon HS, Hirschkorn K, Welsh S, Jurgens T, Eccott L, Heschuk S, Griener \\ GG, Cohen-Kohler JC. 2008. Exploring consumer and pharmacist views on the \\ professional role of the pharmacist with respect to natural health products: a study of \\ focus groups. BMC Complement Altern Med 8:40.
}

\begin{abstract}
Kwan D, Hirschkorn K, Boon H. 2006. U.S. and Canadian pharmacists' attitudes, knowledge, and professional practice behaviors toward dietary supplements: a systematic review. BMC Complement Altern Med 6:31.
\end{abstract}

\begin{abstract}
Medicinal Products Act.
[http://www.ravimiamet.ee/orb.aw/class=file/action=preview/id=5118/EstonianAct10May2005.doc] Accessed 08.02.2010.
\end{abstract}

\author{
Naidu S, Wilkinson JM, Simpson MD. 2005. Australian pharmacists toward \\ complementary and alternative medicines. Ann Pharmacother 39:1456-1461. DOI \\ 10.1345/aph.1G089
}
Olatunde S, Boon H, Hirschorn K, Welsh S, Bajcar J. Roles and responsibilities of pharmacists with respect to natural health products: Key informant interviews. Res Soc Admin Pharm, in press.


Põlluste K, Männik G, Axelsson R. 2005. Public health reforms in Estonia: impact on the health of the population. BMJ 331:210-213

Püüa M. Marketing of some essential oil herbal drugs in Estonia [in Estonian]. Master's thesis, University of Tartu, Tartu, Estonia; 2004, 1-52.

Semple SJ, Hotham E, Rao D, Martin K, Smith CA, Bloustien GF. 2006. Community pharmacists in Australia: barriers to information provision on complementary and alternative medicines. Pharm World Sci 28(6): 366-373.

The Complete German Commission E Monographs, Therapeutic Guide to Herbal Medicines, 1 st ed. 1998. Integrative Medicine Communications, pub; Bk\&CD-Rom edition, 1999.

Thomas KJ, Nicholl JP, Coleman P. 2001. Use and expenditure on complementary medicine in England: a population based survey. Complemet Ther Med 9:2-11.

Tiralongo E, Wallis M. 2008. Attitudes and perceptions of Australian pharmacy students towards complementary and alternative medicine - a pilot study. BMC Complement Altern Med 8:2. 


\author{
Volmer D, Bell JS, Janno R, Raal A, Hamilton DD, Airaksinen MS. 2009. Change in \\ public satisfaction with community pharmacy services in Tartu, Estonia, between 1993 \\ and 2005. Res Social Adm Pharm 5(4): 337-346.
}

\begin{abstract}
Volmer D, Lilja J, Hamilton D. 2007. How well informed are pharmacy customers in Estonia about minor illnesses and over-the-counter medicines. Medicina (Kaunas) 43(1):70-78.
\end{abstract}

Volmer D, Praakli R, Hamilton D. 2006. Some opinions of community pharmacists in
Tartu, Estonia, on the provision of drug information to patients [abstract]. Eur J Pharm Sci 28/Suppl. 1:S37.

Volmer D, Vendla K, Vetka A, Bell JS, Hamilton D. 2008. Pharmaceutical care in
community pharmacies: practice and research in Estonia. Ann Pharmacother 42(7):11041111. 


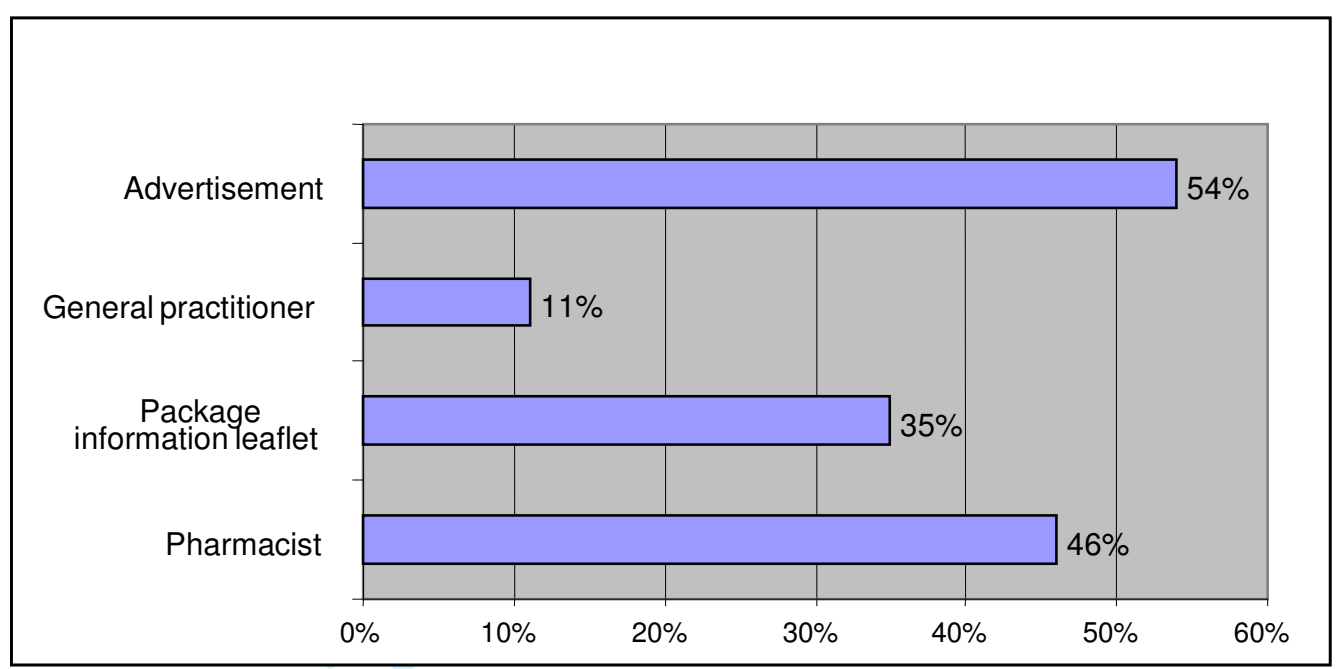

Figure 1. Information sources about herbal products used by Estonian pharmacy customers as reported by Estonian pharmacists. 


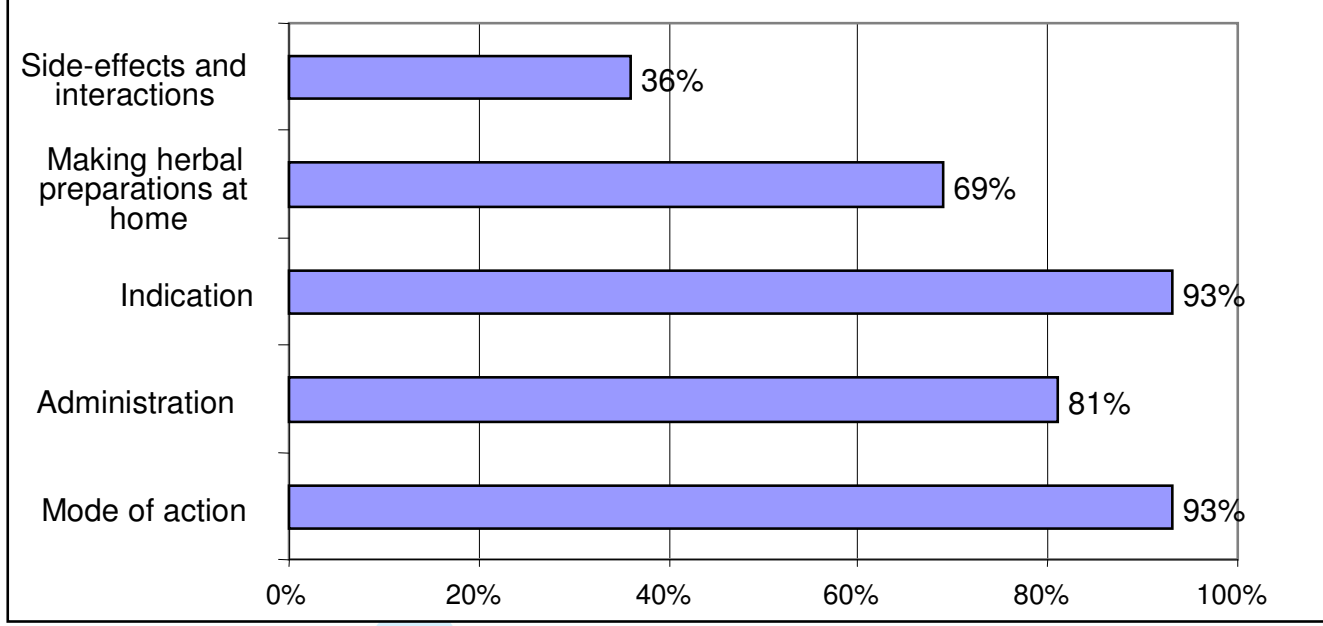

Figure 2. Importance of different types of information concerning herbal products among Estonian pharmacy customers according to the Estonian pharmacists. 


\title{
Self-reported competence of Estonian community pharmacists in relation to herbal products: findings from a health-system in transition
}

\author{
Daisy Volmer ${ }^{1}$, John Lilja ${ }^{2}$, David Hamilton ${ }^{3}$, J Simon Bell ${ }^{4,5}$, Peep Veski ${ }^{1}$ \\ ${ }^{1}$ Department of Pharmacy, University of Tartu, 1 Nooruse St, 50411 Tartu, Estonia \\ ${ }^{2}$ Department of Pharmacy, Åbo Akademi University, Finland \\ ${ }^{3}$ RAPS, University of Glasgow, Scotland \\ ${ }^{4}$ Kuopio Research Centre of Geriatric Care, University of Eastern Finland, Finland \\ ${ }^{5}$ Clinical Pharmacology and Geriatric Pharmacotherapy Unit, School of Pharmacy, \\ Faculty of Health Sciences, University of Eastern Finland, Finland
}

Address for correspondence:

Daisy Volmer, MSc (Pharm)

Lecturer

Department of Pharmacy

Faculty of Medicine

University of Tartu

1 Nooruse Street, 50411 Tartu

Estonia

Phone: +3727375298 , Fax: +3727375289

Email: daisy.volmer@ut.ee

Short title: Competence of Estonian pharmacists in relation to herbal products 


\section{ABSTRACT}

Recent health-system reforms in Estonia have resulted in an increased emphasis on primary health care and evidence-based medicine. Community pharmacies are the primary source of herbal products, and pharmacists have an important role in ensuring the safe and effective use of herbal products. The objective of this study was to explore the self-reported competency of pharmacists and the self-reported provision of community pharmacy services in relation to herbal products. A survey instrument was mailed to a random sample of $154(50 \%)$ community pharmacies in Estonia in February 2005. Responses were received from 114 pharmacists and 6 assistant pharmacists (response rate 77.9\%). Among the respondents, 64.1\% self-evaluated their knowledge of herbal products as good or excellent. However, only $35.0 \%$ reported they experienced no problems in counselling about herbal products, while only $35.8 \%$ recognized the importance of continuing education. Pharmacists attached a high level of importance to providing of information about herbal products' mode of action, administration, potential side-effects and interactions. There was an apparent mismatch between pharmacists' self-reported competency and their self-reported provision of advice about herbal products. Health system reforms in Estonia may need to be accompanied by enhanced training for pharmacists to provide advice about the safe and appropriate use of herbal products.

Key words: herbal products, extended community pharmacy services, Estonia. 


\section{INTRODUCTION}

Complementary and alternative medicine (CAM) has been defined as a group of diverse medical and health care systems, practices, and products that are not generally considered as part of conventional medicine. Herbal products are one component of CAM, and include both herbal supplements sold as food supplements and herbal medications (Barnes, 2003).

Herbal medications contain active constituents with pharmacological effects and have the potential to cause adverse reactions and drug interactions. Herbal medications are usually dispensed by retail pharmacies without prescription and are often regulated as medicinal products (Holst et al., 2009).

The 2007 National Health Interview survey conducted in the US revealed that $74 \%$ of adults and 53\% of children had used herbal supplements in the past 30 days (2007 National Health Interview Survey). A similar increase in the use of CAM has been reported in European countries (Thomas et al., 2001).

In Europe legislation concerning herbal medications was not harmonized until 2001. Prior to European harmonization each country was responsible for its own regulations concerning herbal medications. In Germany, the therapeutic guide to herbal medication issued in 1998 contained descriptions of 380 medicinal plants (The Complete German Commission E Monographs, 1999). Requirements for obtaining a marketing authorisation for herbal medications were first presented in the EU Directive 
2001/83/EC. This directive was later replaced with Directive 2003/63/EC (Commission Directive 2003/63/EC amending Directive 2001/83/EC, 2003).

\section{Healthcare reforms in Estonia}

Estonia is a small northern European country (population 1.3 million) located to the south of Finland. Unlike in many European and North American countries there is a long tradition of herbal product use in Estonia. However, the traditions associated with herbal product use are evolving in line with the recent healthcare reforms. Since independence from Soviet Union was restored in 1991 the Estonian health care system has undergone a process of rapid transition. This transition has involved the shift from a centralized, specialist-orientated system to a system based on primary health care and evidence-based medicine (Põlluste et al., 2005). Under these changes the operation of community pharmacies was transferred from the State to private ownership (Volmer et al., 2008). Estonia joined the European Union (EU) in 2004. Pharmacies in Estonia continue to have a monopoly on the sale of prescription and non-prescription medications, including herbal products. Consumers perceive pharmacists as trustworthy sources of information about prescription and non-prescription drugs (Volmer et al., 2009). However, pharmacy practice and policy in Estonia is increasing shaped by reforms at the European level.

The healthcare reforms described above have created two approaches to the use of herbal products in Estonia. The first approach is based on traditions and practice experience. The second approach is based on evidence-based medicine and scientific research. These approaches are not necessarily mutually exclusive. Estonian 
pharmacists are increasingly required to marry these approaches to meet the healthcare needs and expectations of their customers.

\section{Regulation and use of herbal medications and herbal supplements in Estonia}

Legislation related to herbal medications in Estonia follows EU directives. The State Agency of Medicines (SAM) is the institution responsible for categorization of herbal products as medications or supplements and for licecing of herbal medications. The categorization is made on the basis of the safety of the active components (Medicinal Products Act, 2005). The Estonian Health Care Board is responsible for registration of herbal supplements. However, detailed requirements for the quality, efficacy and safety of herbal supplements have not been developed in Estonia. Currently, the importer of herbal supplements must obtain a quality certificate for each herbal product. Although both herbal medicinal products and supplements are sold in community pharmacies, it is often challenging for pharmacists to access and provide evidence-based information in relation to the quality, efficacy and safety of the herbal supplements.

The use of herbal products has been traditional and popular in Estonia. In 2002 the most popular herbal products were teas for the treatment of minor urinary and upper respiratory tract complaints, followed by stress-relieving remedies and teas to provide a “good night's sleep" (Püüa, 2004). Estonians often use herbal products as the first remedy to treat minor illnesses. Information concerning the mode of action and indication is typically obtained from previous experience or provided by a health care professional, usually a pharmacist (Volmer et al., 2007). 
The only formal education about medicinal plants and herbal products provided to pharmacists in Estonia is during the five-year Master of Pharmacy degree program at the University of Tartu (Evaluation of pharmacy training, 2001). Unlike in many other European countries there are no herbalists in Estonia. In addition, there are very few "health shops" in Estonia from where it is possible to purchase herbal supplements, natural and wellness products, cosmetics and other products.

\section{Attitudes of pharmacists towards herbal products}

A systematic review of 19 studies of US and Canadian pharmacists reported both positive and negative attitudes toward the safety and efficacy of dietary supplements (Kwan, et al., 2006). Despite the fact a large proportion of pharmacists received questions about dietary supplements from patients and other health professionals, pharmacists perceived their knowledge was inadequate and recognized the need for additional training. The need for more training in relation to CAM has also been reported among Australian pharmacy students (Tiralongo and Wallis, 2008). This need may be reinforced by the expectations of patients who consider pharmacists to be knowledgeable about natural health products (Kwan, et al., 2008). Most published studies investigating the attitudes of pharmacists and pharmacy students toward CAM have been conducted in North America, Asia, Australia and England (Barnes and Abbot, 2007; Olatunde, et al., 2010). No previous studies have investigated the attitudes of pharmacists toward use of herbal medications and herbal supplements in this health system in transition. 
The objectives of the study were to (1) explore the self-reported competency of pharmacists in relation to herbal medications and herbal supplements, and (2) investigate the self-reported provision of community pharmacy services in relation to herbal medications and herbal supplements. In the context of the current article the herbal medications and herbal supplements are referred to together as herbal products.

\section{METHODS}

\section{Sample and data collection}

A random sample of $50 \%(n=154)$ of community pharmacies in Estonia was extracted from the Register of pharmacies maintained by the Estonian State Agency of Medicines in February 2005. Each pharmacy in the sample was mailed one copy of the survey instrument and a cover letter. The cover letter requested that the survey instrument should be completed by the pharmacist or assistant pharmacist responsible for managing the sale of non-prescription medications. All pharmacies were provided with a pre-paid addressed envelope to return the survey instrument. A reminder was sent by e-mail to all pharmacies after 2 weeks. All survey instruments were completed anonymously.

\section{Survey instrument}

The survey instrument used in the study was adapted from an instrument previously used to survey a stratified random sample of community pharmacists in the US (Bouldin, et al., 1999). The survey instrument included items related to (1) the respondent's demographic characteristics, (2) the frequency of consumer requests for information about herbal products, (3) the perceived importance of different 
determinants of herbal product use, (4) the perceived importance of different aspects of herbal product information, (5) the respondent's self-reported competency in relation to herbal products, and (6) problems encountered by the respondents in relation to proving advice about herbal products. The content validity of the survey instrument was assessed by a panel of 8 researchers and practitioners with an interest in CAM. The survey instrument was pilot tested for face validity among a convenience sample of five pharmacists. Minor changes to the wording of the items were made based on the feedback received. A copy of the survey instrument can be obtained by contacting the corresponding author.

\section{Statistical analyses}

All data analyses were performed using the Statistical Package for the Social Sciences (SPSS, Version 11.0, Chicago, IL). Differences between groups of pharmacists were compared using chi square tests for categorical variables and independent samples ttests for continuous variables. Younger pharmacists were defined as the respondents aged 25-45 years, whereas older pharmacists were those aged 46-65 years. Urban pharmacies were defined as pharmacies located in the official cities, whereas rural pharmacies were defined as pharmacies located in the villages. Differences in pharmacists' attitudes were examined according to age and location of the pharmacy. The level of statistical significance was set at $\mathrm{p} \leq 0.05$.

\section{RESULTS}

\section{Demographic characteristics of the respondents}


Of the 154 questionnaires distributed $120(77.9 \%)$ were returned, $89(74.1 \%)$ from city pharmacies and $31(25.9 \%)$ from rural pharmacies. Of the respondents, $114(95.0 \%)$ were pharmacists and $6(5.0 \%)$ were assistant pharmacists. All of the respondents were women. The mean age \pm SD of the pharmacists was $42.5 \pm 17.8$ years, and the mean age of the assistant pharmacists was $39.1 \pm 15.4$ years. The pharmacists had a mean of 17.5 \pm 14.6 years working experience while the assistant pharmacists had a mean of $14.5 \pm$ 13.8 years working experience.

\section{Professional competency of pharmacists}

Seventy-seven $(64.1 \%)$ respondents self-reported their professional knowledge regarding herbal products as good or excellent. Continuing education regarding herbal products was rated as important by $35.8 \%$ of the pharmacists $(n=43)$. Pharmacists stated that the best ways of obtaining professional knowledge were written information $(n=75)$ $62.5 \%$ and lectures and seminars $(n=75) 62.5 \%$. Pharmacists were less likely to view visits from drug representatives $(n=47) 39.1 \%$ and electronic databases $(n=43) 35.8 \%$ as important sources of professional knowledge. Pharmacists would like to receive more information about unknown medicinal plants $(n=83) 69.1 \%$, safety $(n=69) 57.5 \%$ and the mode of action $(n=65) 54.2 \%$ of herbal products.

Self-reported professional knowledge was higher among older rather than younger pharmacists $(\mathrm{p}=0.043)$. Younger pharmacists were more likely to prefer electronic databases $(p=0.027)$ and visits from drug representatives $(p=0.032)$ as sources of information about herbal products. Among the respondents, $15.8 \%(n=19)$ had experienced problems counselling about herbal products, $35.0 \%(\mathrm{n}=42)$ reported no 


\section{Customers of herbal products}

According to pharmacists, customers routinely came to the pharmacy for information only $45.8 \%(n=55)$ or to ask for information and purchase herbal products $60.8 \%$ $(n=73)$. According to the pharmacists, the typical customers were a 41-60 year old woman and a 61 years or older man, both from the city. Respondents from urban pharmacies perceived a higher customer interest in herbal products than respondents from rural pharmacies $(\mathrm{p}=0.032)$. More than half of the pharmacists surveyed considered that herbal product advertisements in the mass media was the most common sources of information about herbal products used by pharmacy customers (Figure 1).

Insert Figure 1 here. 
Information about herbal products mode of action, administration, side effects and interactions were considered most important by the survey respondents (Figure 2). Younger pharmacists were more likely than older pharmacists to consider information about safety as important $(\mathrm{p}=0.039)$.

Insert Figure 2 here.

\section{DISCUSSION}

This was the first study in Estonia to investigate the attitudes and knowledge of the pharmacists towards herbal products and their consumption. The results of the study provide an insight into the role of pharmacists in relation to the use of herbal products in this health-system in transition.

Sixty four percent of the respondents self-reported that they possessed good knowledge in relation to herbal products. This self-reported level of knowledge was higher than in surveys of pharmacists conducted in other countries. A Finnish study reported that $38 \%$ and $17 \%$ of pharmacy owners believed they knew sufficient information about herbal medications and herbal supplements respectively (Fock and Pietilä, 2004). A survey of pharmacists and attendees at series of international conferences conducted in Singapore reported that $81 \%$ pharmacists felt they had inadequate skills and knowledge to counsel patients on herbal medications (Koh, et al., 2003). A survey of Australian pharmacists reported that just $15 \%$ reporting they were "very confident" in answering queries about 
safety, interactions or benefits of CAMs (Semple, et al., 2006). This was despite an earlier study finding that $91 \%$ of Australian pharmacists believe it is important to have knowledge of both CAM and conventional medicine to be able to inform patients about their treatment options (Naidu, et al., 2005).

Despite high number of pharmacists self-reporting good knowledge, only $35 \%$ of Estonian pharmacists and assistant pharmacists had not experienced any problems in relation to counselling about herbal products. It is likely, therefore, that the problems experienced by the pharmacists did not relate to their perceived lack of knowledge. Estonian pharmacists may have had difficulty accessing evidence-based information about herbal products. Of 200 herbal products available at Estonian pharmacies in 2001, only $50(25 \%)$ had written patient information leaflets (PILs) that contained no errors (Arjakse, 2002). The most common error related to ascribing medical claims to products classified as food supplements. Obtaining evidence-based information about CAMs is also a problem reported internationally. Sources of information about CAMs among pharmacists surveyed in Singapore included books/magazines (64\%), friends/family (35.7\%), and the Internet (31.4\%) (Koh, et al., 2003). The most common sources of information among Australian pharmacists were books and journal articles. This led the authors of several studies to conclude that there is a need for greater access to CAM resources and education (Semple, et al., 2006; Olatunde, et al., 2010).

It is possible that Estonian pharmacists overestimated their knowledge in relation to CAM and particularly concerning herbal products. While there has been a long tradition of herbal product use in Estonia, recognition of the potential for clinically significant 
herb-drug interactions is more recent (Volmer, et al., 2006). However, as in previous studies (Cuzzolin and Benoni, 2009), issues concerning the safety of herbal products were rarely discussed with pharmacy customers (Volmer, et al., 2006). Scientific evidence concerning the safety and efficacy of CAMs is typically derived from only small number of randomized controlled trials (RCTs) (Hu, et al., 2006). Herb-drug interactions may have not been covered in the undergraduate pharmacy curricula when many of the respondents undertook their university-based training. Pharmacy education about herbal products in Estonia is primarily orientated to botany and the chemical constituents of plants rather than the pharmacological activity of the active substances (Evaluation of pharmacy training, 2001). Tools such as the 22-item Consolidated Standards of Reporting Trials checklist may assist pharmacists interpreting the results of RCTs (Gagnier, et al., 2006). However, further research is required to determine how Estonian pharmacists communicate the risks and benefits of CAM and particularly herbal products to Estonian pharmacy customers.

Our study was conducted within the context of the Estonian health-system. This means our findings may not be directly generalizable to other countries. However, pharmacists in other countries with long traditions of herbal product use face similar challenges. The health-systems in other Baltic and post-Soviet states have been undergoing rapid transformation. There is a long-tradition of herbal product use in Germany. However, unlike in Estonia, herbal products in Germany are also sold by non-pharmacist government regulated practitioners including "Heilpraktiker" (Joos, et al., 2006). The challenge associated with combining traditional and western approaches has also been described in Asian countries (Connett and Lee, 1994). Pharmacognosy is widely 


\section{Study strengths and limitations}

An important strength of the study was that the survey instrument was mailed to a random sample of half of all Estonian community pharmacies, and a good response rate was achieved. Estonian community pharmacists and assistant pharmacists are almost exclusively female. However, a limitation of the study was that it did not capture the attitudes of male pharmacists. In addition only 6 assistant pharmacists participated in the survey. Unlike in many other countries in Europe, the number of pharmacists working at community pharmacies is higher than the number of assistant pharmacists. Another reason for the low participation of assistant pharmacists in the survey could be incorrect following of the instructions. The envelope with the survey instrument could be opened and completed by pharmacy manager. As with other attitudinal surveys, it is not clear whether pharmacists' self-reported attitudes correspond with their actual behaviour in the pharmacy workplace. Further research is also needed to determine consumers' attitudes toward pharmacists as providers of information about CAM.

\section{REFERENCES}


2007 National Health Interview Survey.

[http://www.cdc.gov/NCHS/nhis/nhis_2007_data_release.htm] Accessed 10.06.2010.

Arjakse J. Herbal food supplements and natural products in Estonian community pharmacies [in Estonian]. Master's Thesis. University of Tartu, Tartu, Estonia; 2002, 145.

Barnes J, Abbot NC. 2007. Professional practice and experiences with complementary medicines: a cross-sectional study involving community pharmacists in England. Int $J$ Pharm Pract 15:167-175.

Barnes J. 2003. Quality, efficacy and safety of complementary medicines: fashions, facts and the future. Part I. Regulation and quality. Br J Clin Pharmacol 55:226-233.

Bouldin AS, Smith MC, Garner DD, Szeinbach SL, Frate DA, Croom EM.1999.

Pharmacy and herbal medicine in the US. Soc Sci Med 49:279-289.

Commission Directive 2003/63/EC amending Directive 2001/83/EC of the European Parliament and of the Council on the Community code relating to medicinal products for human use. [http://www.emea.europa.eu/pdfs/human/pmf/2003-63-EC.pdf] Accessed 10.06.2010.

Connett GJ, Lee BW. 1994. Treating childhood asthma in Singapore: when West meets 
East. BMJ 308(6939): 1282-1284.

Cuzzolin L, Benoni G. 2009. Attitudes and knowledge toward natural products safety in the pharmacy setting: an Italian study. Phytother Res 23: 1018-1023.

Evaluation of pharmacy training. Department of Pharmacy, Faculty of Medicine, University of Tartu. Tartu University, Tartu 2001. [http://www.ut.ee/ARFA/report.pdf] Accessed 10.06.2010.

Fock J, Pietilä K. 2004. The knowledge of legislation and information sources on natural health products among pharmacy owners in Finland. Seguim Farmacoter 2:7385.

Gagnier JJ, Boon H, Rochon P, Moher D, Barnes J, Bombardier C. 2006. Recommendations for reporting randomized controlled trials of herbal interventions: Explanation and elaboration. J Clin Epidemiol 59(11):1134-1139.

Holst L, Wright D, Nordeng H, Haavik S. 2009. Use of herbal preparations during pregnancy: Focus group discussion among expectant mothers attending a hospital antenatal clinic in Norwich, UK. Complement Ther Clin Pract 15:225-229.

Hu Z, Yang X, Ho PC, Chan SY, Heng PW, Chan E, Duan W, Koh HL, Zhou S.2005. Herb-drug interactions: a literature review. Drugs 65:1239-1282.

Joos S, Rosemann T, Szecsenyi J, Hahn EG, Willich SN, Brinkhaus B. 2006. Use of complementary and alternative medicine in Germany - a survey of patients with inflammatory bowel disease. BMC Complement Altern Med 6:19. 
Koh H-L, Teo H-H, Ng H-L. 2003. Pharmacists' patterns of use, knowledge, and attitudes toward complementary and alternative medicine. J Altern Complement Med 9(1): 51-63.

Kwan D, Boon HS, Hirschkorn K, Welsh S, Jurgens T, Eccott L, Heschuk S, Griener GG, Cohen-Kohler JC. 2008. Exploring consumer and pharmacist views on the professional role of the pharmacist with respect to natural health products: a study of focus groups. BMC Complement Altern Med 8:40.

Kwan D, Hirschkorn K, Boon H. 2006. U.S. and Canadian pharmacists' attitudes, knowledge, and professional practice behaviors toward dietary supplements: a systematic review. BMC Complement Altern Med 6:31.

Medicinal Products Act.

[http://www.ravimiamet.ee/orb.aw/class=file/action=preview/id=5118/EstonianAct10May2005.doc] Accessed 10.06.2010.

Naidu S, Wilkinson JM, Simpson MD. 2005. Australian pharmacists toward complementary and alternative medicines. Ann Pharmacother 39:1456-1461. DOI 10.1345/aph.1G089 
Olatunde S, Boon H, Hirschorn K, Welsh S, Bajcar J. 2010. Roles and responsibilities of pharmacists with respect to natural health products: Key informant interviews. Res Soc Admin Pharm 6(1):63-69.

Põlluste K, Männik G, Axelsson R. 2005. Public health reforms in Estonia: impact on the health of the population. BMJ 331:210-213

Püüa M. Marketing of some essential oil herbal drugs in Estonia [in Estonian]. Master's thesis, University of Tartu, Tartu, Estonia; 2004, 1-52.

Semple SJ, Hotham E, Rao D, Martin K, Smith CA, Bloustien GF. 2006. Community pharmacists in Australia: barriers to information provision on complementary and alternative medicines. Pharm World Sci 28(6): 366-373.

The Complete German Commission E Monographs, Therapeutic Guide to Herbal Medicines,1st ed. 1998. Integrative Medicine Communications, pub; Bk\&CD-Rom edition, 1999.

Thomas KJ, Nicholl JP, Coleman P. 2001. Use and expenditure on complementary medicine in England: a population based survey. Complemet Ther Med 9:2-11.

Tiralongo E, Wallis M. 2008. Attitudes and perceptions of Australian pharmacy students towards complementary and alternative medicine - a pilot study. $B M C$ Complement Altern Med 8:2. 


\author{
Volmer D, Bell JS, Janno R, Raal A, Hamilton DD, Airaksinen MS. 2009. Change in \\ public satisfaction with community pharmacy services in Tartu, Estonia, between 1993 \\ and 2005. Res Social Adm Pharm 5(4): 337-346.
}

Volmer D, Lilja J, Hamilton D. 2007. How well informed are pharmacy customers in Estonia about minor illnesses and over-the-counter medicines. Medicina (Kaunas) 43(1):70-78.

Volmer D, Praakli R, Hamilton D. 2006. Some opinions of community pharmacists in Tartu, Estonia, on the provision of drug information to patients [abstract]. Eur J Pharm Sci 28/Suppl. 1:S37.

Volmer D, Vendla K, Vetka A, Bell JS, Hamilton D. 2008. Pharmaceutical care in community pharmacies: practice and research in Estonia. Ann Pharmacother 42(7):1104-1111. 


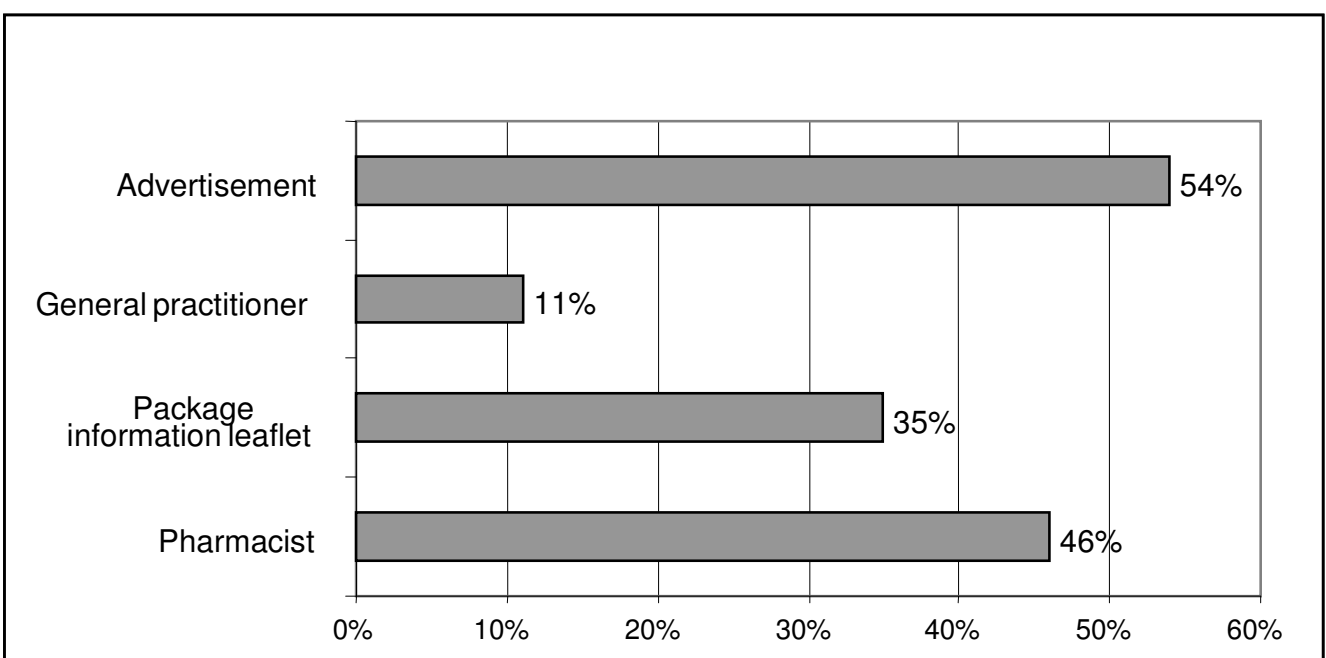

Figure 1. Information sources about herbal products used by Estonian pharmacy customers as reported by Estonian pharmacists. 
Side-effects and interactions

Making herbal preparations at home

Indication

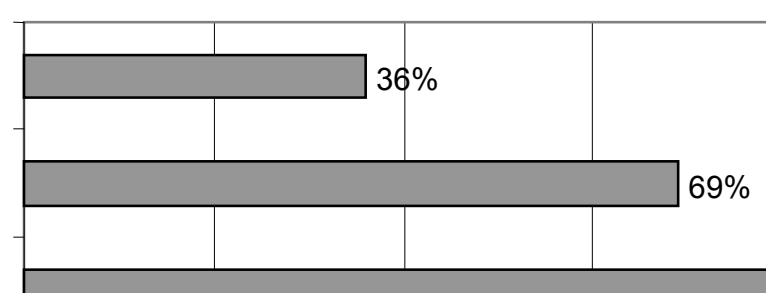

Administration
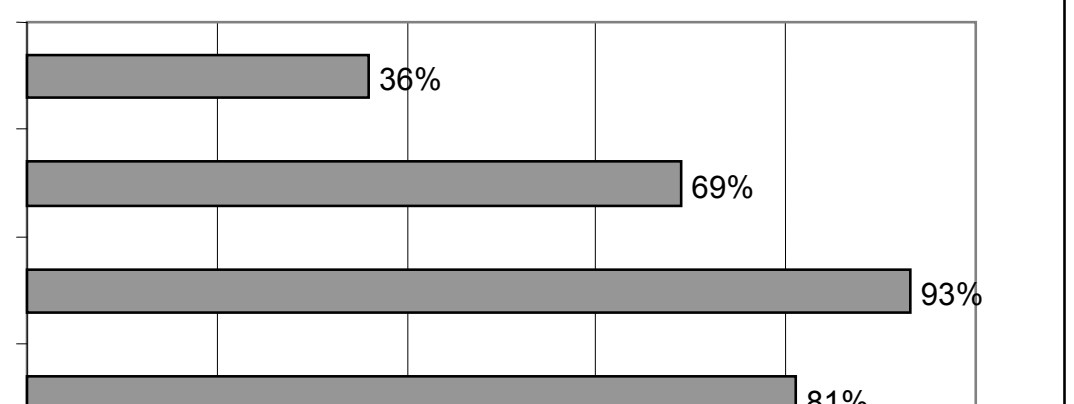

Mode of action

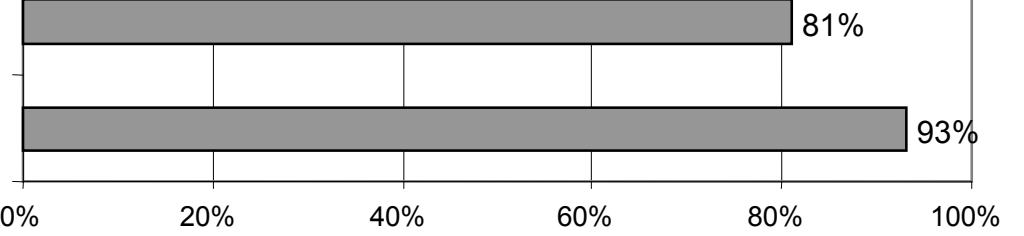

Figure 2. Importance of different types of information concerning herbal products among Estonian pharmacy customers according to the Estonian pharmacists. 